\title{
Iron and zinc deficiencies in China: what is a feasible and cost-effective strategy?
}

\author{
Guansheng $\mathrm{Ma}^{1,2, *}$, Ying Jin ${ }^{1}$, Yanping $\mathrm{Li}^{1,2}$, Fengying Zhai ${ }^{1}$, Frans J Kok ${ }^{2}$, \\ Evert Jacobsen ${ }^{2}$ and Xiaoguang Yang ${ }^{1}$ \\ ${ }^{1}$ National Institute for Nutrition and Food Safety, Chinese Center for Disease Control and Prevention, 29 Nan \\ Wei Road, Beijing 100050, People's Republic of China: ${ }^{2}$ Division of Human Nutrition, Wageningen University, \\ Wageningen, The Netherlands
}

Submitted 6 March 2007: Accepted 23 July 2007: First published online 26 September 2007

\begin{abstract}
In order to prioritise interventions for micronutrient deficiencies in China, the populations affected by iron and zinc deficiencies were assessed based on data from the 2002 China National Nutrition and Health Survey. The costs and costeffectiveness of supplementation, food diversification and food fortification were estimated using the standard World Health Organization ingredients approach. Results indicated that $30 \%$ of children $(<2$ years), adults ( $>60$ years), pregnant and lactating women, and $20 \%$ of women of reproductive age were anaemic, some 245 million people. Approximately 100 million people were affected by zinc deficiency (zinc intake inadequacy and stunting), the majority living in rural areas. Among interventions on iron and zinc deficiency, biofortification showed the lowest costs per capita, I\$0.01 (international dollars), while dietary diversification through health education represented the highest costs at I\$1148. The costeffectiveness of supplementation, food fortification and dietary diversification for iron deficiency alone was I\$179, I\$66 and I\$103 per disability-adjusted life-year (DALY), respectively. Data for biofortification were not available. For zinc deficiency, the corresponding figures were I\$399, I\$153 and I\$103 per DALY, respectively. In conclusion, iron and zinc deficiencies are of great public health concern in China. Of the two long-term intervention strategies, i.e. dietary diversification and biofortification with improved varieties, the latter is especially feasible and cost-effective for rural populations. Supplementation and fortification can be used as short-term strategies for specific groups.
\end{abstract}

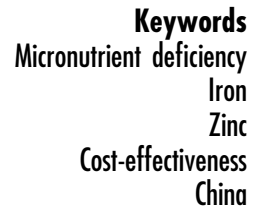

The latest World Health Organization (WHO) estimates reveal that undernutrition is an underlying cause of $53 \%$ of all deaths in children $<5$ years of age $\mathrm{e}^{1}$. It has been estimated that more than 2 billion of the world's population, nearly all in developing countries, are irondeficient $^{2,3}$. Billions of individuals are also at risk for zinc deficiency ${ }^{4}$.

Micronutrient deficiency not only affects the health and development of people ${ }^{5-9}$, but also hinders the social and economic development of countries. It is estimated that the loss in economic productivity due to iron deficiency in China is more than $3.6 \%$ of the gross national product ${ }^{10}$.

The causes of micronutrient deficiencies include inadequate intakes, impaired absorption and/or utilisation, excessive losses, increased physiological need or the combination of these factors ${ }^{11}$. Insufficient intake and poor bioavailability are major causes in developing countries ${ }^{12-14}$. Micronutrient content and bioavailability can be improved by either increasing the quantity of a micronutrient or increasing enhancing factors/decreasing inhibiting factors in foods using different techniques or sources. Strategies for increasing the effective supply of nutrients fall into two categories, supplementation and food-based approaches. Supplementation is the addition of an element to the diet to solve insufficiency. Foodbased approaches consist of food diversification, i.e. increasing the number of different foods or food groups consumed over a given reference period ${ }^{15}$, and food fortification. Food fortification is the addition of an ingredient to food to increase the concentration of a particular element, while biofortification is the process of increasing the absolute content or bioavailable concentration of an element in edible portions of crop plants through agronomic intervention or genetic selection ${ }^{16}$. Supplementation, food fortification and dietary diversification have been the three most widely applied interventions for micronutrient deficiency in past decades. Each intervention has its advantages and disadvantages ${ }^{17}$. 
Information on the magnitude of micronutrient deficiencies and the cost and cost-effectiveness of intervention strategies is needed for prioritising their significance and for developing public policy. However, at the moment, there is a lack of this kind of information in China. The China National Nutrition and Health Survey (CNNHS) conducted in 2002 makes it possible to assess the current situation of micronutrient deficiencies in China and provide information for policy-makers. Therefore, the aims of the present study were to: (1) estimate the populations affected by iron and zinc deficiencies; (2) identify the vulnerable population for intervention; (3) estimate the cost and cost-effectiveness of three interventions; and (4) provide information for policy-makers for developing intervention strategies.

\section{Methods}

\section{Estimation of populations with iron and zinc deficiencies}

The 2002 CNNHS was a nationally representative survey, which recruited 243479 individuals from 71971 households of 132 sites in 31 provinces, autonomous regions and municipalities ${ }^{18}$. More detailed information on study design $^{19}$ and quality control ${ }^{20}$ has been given elsewhere.

Haemoglobin was determined using the cyanomethaemoglobin method (National Committee for Clinical Laboratory Standards, 1994). The WHO definition was used for defining anaemia ${ }^{12}$. The haemoglobin values were adjusted according to the altitude of the study sites. Anaemia prevalence was adjusted using data of the 2000 China National Population Census ${ }^{21}$ in order to eliminate the difference in proportion between the sample and the whole population. The population with iron-deficiency anaemia (IDA) was calculated according to the prevalence of anaemia and the ratio of IDA to anaemia ${ }^{22-25}$.

Fasting body weight and height (length) of subjects were measured following the standard procedure ${ }^{26}$ by trained investigators. The duplicate measurements in subgroups showed a high reproducibility. The absolute technical error of the measurement (TEM) for weight and height were 2.85 and 2.54 , respectively, while the relative TEM was $5.6 \%$ and $1.73 \%$, respectively. Stunting was defined by $Z$-score of height-for-age according to WHO criteria $^{27}$.

Information on food intake was collected using the 24-hour dietary recall method for three consecutive days (two weekdays and one weekend day) by trained interviewers $^{19}$. Zinc intake was calculated using the dietary recall data in conjunction with the China Food Composition Table ${ }^{28}$. The bioavailability of dietary zinc is $50 \%$, $30 \%$ and $15 \%$, respectively, for people with dietary phytate/zinc ratio in the range $<5,5-15$ and $>15^{29}$. The WHO normative requirements ${ }^{29}$ of people with different bioavailability were used to assess the inadequacy of zinc intake. The percentage of people with zinc intake below the WHO normative requirement at different phytate/zinc molar ratios was calculated ${ }^{30-32}$. The estimation of zinc deficiency is based on zinc inadequacy and not any biochemical markers.

The prevalences of anaemia, stunting and zinc intake inadequacy, in combination with data from the 2000 China National Population Census ${ }^{21}$, were used for estimation of the absolute number of affected subjects.

\section{Food sources of iron and zinc}

The contribution of individual foods to iron/zinc was calculated by summing the amount of iron/zinc consumed from each food by all subjects in each age group and dividing it by the total intake from all foods for all subjects $^{33}$.

\section{Estimated costs and cost-effectiveness of different interventions}

The costs per capita and cost-effectiveness of supplementation and fortification for iron and zinc were obtained from the results of the total population-level costs for the Western Pacific Region B, for the year 2000, by $\mathrm{WHO}^{34}$. The standard WHO ingredients approach, with separate specification of units of utilisation and costs, is adopted ${ }^{34}$. Costs are expressed in international dollars (I\$) to facilitate more meaningful comparisons across regions. An international dollar has the same purchasing power as the US\$ has in the USA. Costs in local currency units are converted to I\$ by use of the PPP (purchasing power parity) exchange rate rather than official exchange rates ${ }^{35}$. The costs of an intervention programme are costs per year (I\$, millions) per one million population, i.e. cost per capita. The cost-effectiveness is measured by the cost per disability-adjusted life-year (DALY) saved.

The costs per capita and cost-effectiveness of health education through mass media for the entire population ${ }^{36}$ were used for dietary diversification through health education because more specific information was not available.

The costs of biofortification were calculated based on the literature ${ }^{37}$. The areas of rice and wheat harvested were $28 \times 10^{6}$ and $22 \times 10^{6}$ ha, respectively, in China ${ }^{38}$. For a single staple crop, the estimated central fixed cost of developing iron-dense/zinc-dense varieties over 10 years is I $\$ 12.5$ million $^{37}$. The central fixed costs include costs of nutritional studies to establish efficacy and to demonstrate impact after adoption. The cost for developing irondense/zinc-dense rice and wheat varieties is I\$25 million for a 10 -year period.

The estimated cost for adaptive breeding per province for growing conditions in China for the same 10-year period is I $\$ 2.5$ million. There are 17 provinces for growing 
rice and nine provinces for growing wheat. The estimated cost of two crops in those areas is $\mathbf{\$} \$ 65$ million $\left[\left(17 \times 2.5 \times 10^{6}\right)+\left(9 \times 2.5 \times 10^{6}\right)\right]$.

The extension costs are estimated to be I\$ 1 per adopted hectare. If adoption occurs on $50 \%$ of the rice and wheat areas in China, there will be $25 \times 10^{6}$ ha [ $(50 \%$ of $\left.28 \times 10^{6}\right)+\left(50 \%\right.$ of $\left.\left.22 \times 10^{6}\right)\right]$. Thus the fixed undiscounted extension cost is I\$25 million. The total investment in iron-dense/zinc-dense rice and wheat is therefore I\$115 million over 10 years, or I\$11.5 million per annum. The estimated cost per capita is I\$0.01 (Table 4).

\section{Results}

\section{Populations affected by iron and zinc deficiencies in Cbina}

Table 1 presents the prevalence of anaemia and the estimated populations affected by anaemia and IDA in China. The overall prevalence of anaemia was $20.1 \%$ and $31.1 \%$ of children $<2$ years were anaemic. Nearly $30 \%$ of adults $>60$ years, pregnant and lactating women, and $20 \%$ of women of reproductive age were anaemic. The estimated population affected by anaemia was 245 million, and 208 million of these were due to iron deficiency. Three-quarters of these affected populations were found in rural areas.

The prevalence of zinc intake inadequacy and stunting, and the estimated affected populations in China, is shown

Table 1 Prevalence of anaemia, and estimated affected populations in China

\begin{tabular}{|c|c|c|c|}
\hline & \multirow[b]{2}{*}{$\begin{array}{c}\text { Prevalence } \\
(\%)\end{array}$} & \multicolumn{2}{|c|}{$\begin{array}{l}\text { Estimated affected } \\
\text { population (million) }\end{array}$} \\
\hline & & Anaemia & $\begin{array}{l}\text { Iron-deficiency } \\
\text { anaemia* }^{*}\end{array}$ \\
\hline \multicolumn{4}{|c|}{ Entire sample $(0-101$ years $)$} \\
\hline All & 20.1 & 245.4 & 208.6 \\
\hline Urban & 18.2 & 61.8 & 52.5 \\
\hline Rural & 20.8 & 183.6 & 156.1 \\
\hline \multicolumn{4}{|c|}{ Children ( $<2$ years) } \\
\hline All & 31.1 & 12.7 & 10.8 \\
\hline Urban & 29.3 & 2.9 & 2.5 \\
\hline Rural & 31.6 & 9.8 & 8.3 \\
\hline \multicolumn{4}{|c|}{ Adults (>60 years) } \\
\hline All & 29.1 & 37.2 & 31.6 \\
\hline Urban & 22.5 & 7.8 & 6.6 \\
\hline Rural & 31.5 & 29.4 & 24.5 \\
\hline \multicolumn{4}{|c|}{ Women ( $15-50$ years) } \\
\hline All & 19.9 & 68.3 & 58.1 \\
\hline Urban & 18.8 & 19.4 & 16.5 \\
\hline Rural & 20.4 & 48.9 & 41.6 \\
\hline \multicolumn{4}{|c|}{ Pregnant women } \\
\hline All & 28.9 & 3.1 & 2.6 \\
\hline Urban & 25.3 & 1.2 & 1.0 \\
\hline Rural & 30.4 & 1.9 & 1.6 \\
\hline \multicolumn{4}{|c|}{ Lactating women } \\
\hline All & 29.5 & 6.2 & 5.3 \\
\hline Urban & 27.3 & 2.4 & 2.0 \\
\hline Rural & 30.4 & 3.8 & 3.3 \\
\hline
\end{tabular}

${ }^{\star}$ Anaemia due to iron deficiency is estimated at $85 \%$. in Table 2. More rural residents had inadequate zinc intake than their urban counterparts (8.2\% vs. 4.6\%). Zinc intake inadequacy among rural children was two- to threefold greater in comparison with their urban counterparts. In addition, $14.3 \%$ of rural children $<5$ years were stunted. The estimated populations affected by zinc intake inadequacy and stunting were 86 million and 10 million, respectively, and the majority of them were living in rural areas.

Food sources of iron and zinc for people in Cbina The food sources of iron and zinc are presented in Table 3. The highest proportions of iron (47.7\%) and zinc (53.9\%) were found in staple foods including rice, wheat and their products. Staple foods provided even more iron $(52.1 \%$ vs. 37.0\%) and zinc (58.9\% vs. 41.4\%) for rural residents than for their urban counterparts. As expected, animal products provided more iron (19.6\% vs. 10.5\%) and zinc (34.5\% vs. 18.6\%) for urban residents than their rural counterparts because of their higher meat intake. Staple foods were also the major sources of phytate for both rural $(82.1 \%)$ and urban $(77.6 \%)$ residents. Vegetables contributed about $17 \%$ of iron, $11 \%$ of zinc, and only $7 \%$ of phytate.

\section{Costs per capita and cost-effectiveness of different interventions}

Table 4 presents the costs per capita and the cost-effectiveness of four interventions for iron and zinc deficiencies. For intervention on iron deficiency, the costs per

Table 2 Prevalence of zinc intake inadequacy and stunting, and estimated affected populations in China

\begin{tabular}{lcc}
\hline & $\begin{array}{c}\text { Prevalence } \\
(\%)\end{array}$ & $\begin{array}{c}\text { Estimated affected } \\
\text { population (million) }\end{array}$ \\
\hline Zinc intake inadequacy & & \\
Entire sample (2-101 years) & & \\
$\quad$ All & 7.1 & 86.0 \\
$\quad$ Urban & 4.6 & 15.3 \\
$\quad$ Rural & 8.2 & 70.7 \\
Children (2-3 years) & & \\
$\quad$ Urban & 7.4 & 0.5 \\
$\quad$ Rural & 24.0 & 5.0 \\
Children (4-6 years) & & \\
$\quad$ Urban & 12.0 & 1.3 \\
$\quad$ Rural & 16.0 & 6.1 \\
Children (7-10 years) & & 1.4 \\
$\quad$ Urban & 8.4 & 8.6 \\
$\quad$ Rural & 14.0 & 3.9 \\
Children (11-18 years) & & 23.6 \\
$\quad$ Urban & 8.4 & \\
$\quad$ Rural & 17.6 & \\
$\quad$ Stunting & & 9.8 \\
Children (<5 years) & & 0.8 \\
$\quad$ All \\
$\quad$ Urban \\
Rural & 14.3 & 9.0 \\
\hline
\end{tabular}


Table 3 Food sources of iron, zinc and phytate of people in China (\%)

\begin{tabular}{lrrr}
\hline Food type & All & Urban & Rural \\
\hline Iron & & & \\
$\quad$ Rice and products & 22.1 & 16.8 & 24.3 \\
Wheat and products & 25.6 & 20.2 & 27.8 \\
Vegetables & 16.9 & 16.1 & 17.2 \\
Animal foods & 13.1 & 19.6 & 10.5 \\
Others & 22.3 & 27.3 & 20.2 \\
Zinc & & & \\
Rice and products & 33.8 & 25.5 & 37.2 \\
Wheat and products & 20.1 & 15.9 & 21.7 \\
Animal foods & 23.3 & 34.5 & 18.6 \\
Vegetables & 10.9 & 9.8 & 11.3 \\
$\quad$ Others & 10.9 & 14.3 & 11.2 \\
Phytate & & & \\
Rice and products & 52.3 & 50.9 & 52.7 \\
Wheat and products & 28.9 & 26.7 & 29.4 \\
Vegetables & 7.4 & 7.6 & 7.3 \\
Others & 11.4 & 14.7 & 10.6 \\
\hline
\end{tabular}

Table 4 Cost per capita and cost-effectiveness of the interventions

\begin{tabular}{lcc}
\hline & $\begin{array}{c}\text { Cost per } \\
\text { capita (I\$) }\end{array}$ & $\begin{array}{c}\text { Average cost (I\$) } \\
\text { per DALY saved }\end{array}$ \\
\hline Iron deficiency & & \\
$\quad$ Supplementation & 11.4 & 179 \\
Food fortification & 0.06 & 66 \\
Dietary diversification & 1148 & 103 \\
Biofortification & 0.01 & $\mathrm{NA}$ \\
Zinc deficiency & & \\
Supplementation & 0.05 & 399 \\
Zinc fortification & 0.01 & 153 \\
Dietary diversification & 1148 & 103 \\
Biofortification & 0.01 & $\mathrm{NA}$
\end{tabular}

I\$ - international dollars; DALY - disability-adjusted life-year; NA - not applicable.

capita per year of dietary diversification, supplementation, food fortification and biofortification were estimated to be I\$1148, I\$11.4, I\$0.06 and I\$0.01, respectively. The cost-effectiveness for supplementation, food fortification and dietary diversification were I\$179, I\$66 and I\$103 per DALY, respectively, and that for biofortification could not be determined.

For zinc deficiency intervention, the costs per capita per year of dietary diversification, supplementation, food fortification and biofortification were I\$1148, I\$0.05, I\$0.01 and $\mathbf{I} \$ 0.01$, respectively. The cost-effectiveness for supplementation, food fortification and dietary diversification were I\$399, I\$153 and I\$103 per DALY, respectively.

\section{Discussion}

The present study indicated that iron and zinc deficiencies affect over 300 million people in China, most of them being women and children living in rural areas.

It turned out that staple foods provide about 50\% of iron and zinc intake but, at the same time, they contain most of the phytate, which inhibits the bioavailability of iron and zinc. The costs per capita and the cost-effectiveness for the different intervention strategies varied considerably. This information is crucial for developing public health policy in China.

The first strength of the present study is that it used the latest nationally representative data for estimation of the magnitude of iron and zinc deficiency and for the identification of vulnerable groups. The second strength is the quality of the dietary assessment method, including an updated food composition table. Moreover, the standard WHO ingredients approach was used for estimating the costs and cost-effectiveness of the different interventions. One limitation is that the data we used to estimate iron deficiency was IDA, not including mild-to-moderate iron deficiency in which anaemia is absent; therefore, there was an underestimation of the prevalence of iron deficiency to some extent. As the dietary intake data covered only a few days which did not represent the 'usual intakes', we might have overestimated the zinc inadequacy prevalence in this study. Another limitation is that the cost-effectiveness of biofortification could not be estimated because there are not enough biofortified foods available at present and studies examining the effectiveness of biofortified foods on the micronutrient status of human subjects are lacking.

Interventions to end micronutrient malnutrition are known to be the most cost-effective investments in the health sector ${ }^{39,40}$. Actions to solve this problem comprehensively and sustainably would cost less than $0.3 \%$ of the gross domestic product (GDP). In contrast, failure to take action would result in a loss of $2-3 \%$ of the GDP ${ }^{41}$. The economic and social pay-offs from intervention programmes can reach as high as 84 times the programme costs.

Supplementation, food fortification and dietary diversification have been the three most widely applied interventions for micronutrient deficiencies in past decades. Supplementation of vitamin A, iron and zinc has been proved effective in developing countries for the improvement of mineral status in deficient individuals ${ }^{17,42-45}$. However, its sustainability is questionable because various economic, social and political difficulties might diminish the effectiveness at reaching all of the people at risk ${ }^{46}$. Considering the high prevalence of iron and zinc deficiencies among important subpopulations in China and recommendations ${ }^{47,48}$, supplementation programme(s) targeting the population 'at risk' can be considered a short-term intervention.

Fortification has been successfully applied to improve the nutritional quality of the food supply in industrialised countries for many decades ${ }^{49-52}$, but has only recently been adopted in developing countries ${ }^{53,54}$. It has the advantage of wide coverage, being easy to implement and cost-effectiveness ${ }^{55}$. The challenge is to reach the most needed subset of the population who seldom consume processed cereals. In China, more than $60 \%$ of the 
population lives in rural areas and almost all households have their staples processed at the local, small mill instead of getting processed cereals from the market. It is a challenge to reach these people and the subpopulations living in remote and mountainous areas. No further national programme for iron fortification is needed in China at present because programmes of wheat flour and soy sauce fortification have been implemented since $2003^{41}$.

Lack of dietary diversity is a particular problem among the rural population in China because their diets are predominantly based on staples and often include low amounts of animal foods ${ }^{56}$. The permanent solution is to persuade people to change their diets. Once the programme succeeds, it will sustain and require no regular re-supply of supplementation/fortification. However, usually it is difficult to change dietary practices. Micronutrient-rich foods are often expensive, and the poor cannot afford them ${ }^{15}$. Although the costs are high, from a sustainability perspective it would be useful to develop a national health education programme and combine it with existing programmes, such as the Poverty Reduction and Health Education for Peasants, so that resources will be used in the best way. The cost and cost-effectiveness data we used for dietary diversification are in fact the cost of mass media on health education on lowering systolic blood pressure and cholesterol; owing to the paucity of relative research, more studies in this area are surely needed in the future.

In recent years, more and more scientists in the fields of both of agriculture and nutrition have come to believe that biofortification is a promising, cost-effective and sustainable intervention for alleviating micronutrient deficiency, especially for developing countries. Genetic variation in concentrations of minerals and phytate exists among cultivars, which makes the selection of nutritionally appropriate breeding materials possible ${ }^{16}$. However, most biofortified cereals are still in the development stage at present, and only one small randomised controlled trial $^{57}$ on iron-biofortified rice has been conducted. Zincdense wheat varieties have been developed and are already being grown on a commercial basis in Australia (Adelaide, Victoria ${ }^{16}$ ).

Biofortification has the potential to have a great impact on the micronutrient intake of people in China, who derive about $50 \%$ of their iron and zinc from two staples, rice and wheat, and their products. The bioavailability of iron and zinc in the diet depends not only on the absolute content of iron, zinc and phytate, but also on the relative content (i.e. the molar ratio of phytate to minerals). Simultaneously increasing the mineral content and decreasing the phytate content of staple foods through biofortification would have a direct and profound influence on the nutritional status of the entire population. But more trials are needed to demonstrate that these new biofortifed cereals are efficacious in preventing deficiencies of iron and zinc. Biofortification of vegetables can also be considered as an option, especially with adequate energy in the food, because vegetables are rich in ascorbic acid which may enhance iron absorption and play an important role in the daily diet. Biofortification provides a feasible means of reaching populations in remote and rural areas, delivering naturally fortified foods to people with limited access to supplementation/commercially marketed fortified foods ${ }^{37}$. In this way, there would be no need to change dietary practices. Biofortification is cost-effective $\mathrm{s}^{57,58}$, although detailed costeffectiveness estimates are not available. The annually recurrent costs are low after the one-time investment to develop varieties, and germplasm with increased minerals and decreased phytate content can be shared internationally. Moreover, as the trace mineral requirements between human and plant nutrition are similar, biofortification could improve human nutrition as well as plant yield in a way that is environmentally beneficial ${ }^{43,44}$. However, there are still a lot of questions left to be answered, like regulation and policy, safety, bioavailability, cost-effectiveness and consumer acceptance, before it can be widely applied. A link between the agriculture and nutrition sector needs to be established to solve the problem of micronutrient deficiency. The agricultural sector must adopt a specific goal of improving human nutrition and health, while the nutrition and health sectors must adopt agricultural interventions as a primary tool to fight malnutrition ${ }^{59}$.

It is acknowledged that no single intervention by itself can solve the micronutrient deficiency problem. The success of biofortification does not mean there is no need for other strategies in the future. Supplementation, fortification and dietary diversification will continue to be used not only for ending nutritional deficiencies but also for preventing diet-related diseases ${ }^{60}$.

In conclusion, iron and zinc deficiencies affect a large number of people in China, especially women and children in rural areas. Supplementation and fortification can be used as short-term interventions for micronutrient deficiencies, while dietary diversification and biofortification could be long-term interventions. Biofortification might be a feasible, cost-effective and sustainable solution for the rural population in China.

\section{Acknowledgements}

The 2002 China National Nutrition and Health Survey was supported by the Ministry of Health and the Ministry of Science and Technology, China (2001DEA30035, 2003DIA6N008). We thank all team members and all participants from 31 provinces. We are very appreciative of the support of UNICEF, WHO, Unilever China and the Danone Nutrition Institute China. 


\section{References}

1 Bryce J, Boschi-Pinto C, Shibuya K, Black RF. WHO estimates of the causes of death in children. Lancet 2005 ; 365: $1147-52$.

2 World Health Organization (WHO). World Health Report 2002. Reducing Risks, Promoting Healthy Life. Geneva: WHO, 2002.

3 United Nations Administrative Committee on Coordination, Sub-committee on Nutrition (ACC/SCN). Fourth Report on the World Nutrition Situation. Geneva: ACC/SCN \& International Food Policy Research Institute, 2000.

4 Prasad AS. Zinc deficiency has been known for 40 years but ignored by global health organizations. British Medical Journal 2003; 356: 422-4.

5 Pollitt E. Iron deficiency and cognitive function. Annual Review of Nutrition 1993; 13: 521-37.

6 Walter T, De Andraca I, Chadud P, Perales CG. Iron deficiency anemia: adverse effects on infant psychomotor development. Journal of Pediatrics 1989; 84: 7-17.

7 Soewonde S, Husaini M, Pollitt E. Effects of iron deficiency on attention and learning processes on preschool children: Bandung, Indonesia. American Journal of Clinical Nutrition 1989; 50: 675-86.

8 Lozoff B. Behavioral alterations on iron deficiency. Advances in Pediatrics 1988; 35: 331-60.

9 Levin HM, Pollitt E, Galloway R, McGuire J. Micronutrient deficiency disorders. In: Jamison DT, Mosley WH, eds. Disease Control Priorities in Developing Countries. New York: Oxford University Press/World Bank, 1993.

10 Ross J, Chen C, He W, Gu G, Wang Y, Fu Z, et al. Effects of malnutrition on economic productivity in China as estimated by PROFILES. Biomedical and Environmental Sciences 2003; 16: 195-205.

11 Gibson RS. Zinc: the missing link in combating micronutrient malnutrition in developing countries. Proceedings of the Nutrition Society 2006; 65: 51-60.

12 United Nations Children's Fund/United Nations University/ World Health Organization (WHO). Iron Deficiency Anaemia: Assessment, Prevention, and Control. A Guide for Programme Managers. WHO/NHD/01.3. Geneva: WHO, 2001.

13 Willett W. Nutritional Epidemiology, 2nd ed. New York: Oxford University Press, 1998.

14 Tatala S, Svanberg U, Mduma B. Low dietary iron availability is a major cause of anemia: a nutrition survey in the Lindi District of Tanzania. American Journal of Clinical Nutrition 1998; 68: 171-8.

15 Ruel MT. Operationalizing dietary diversity: a review of measurement issues and research priorities. Journal of Nutrition 2003; 133: 3911S-26S.

16 White PJ, Broadley MR. Biofortifying crops with essential mineral elements. Trends in Plant Science 2005; 10: 586-92.

17 Allen LH. Interventions for micronutrient deficiency control in developing countries: past, present and future. Journal of Nutrition 2003; 133: 3875S-8S.

18 Wang L. Report of China Nationwide Nutrition and Health Survey 2002 (1): Summary Report. Beijing: People's Medical Publishing House, 2005; 18-45.

19 Yang X, Kong L, Zhai F, Ma G, Jin S. The 2002 China National Nutrition and Health Survey. Chinese Journal of Epidemiology 2005; 26: 471-4.

20 Piao J, Zhang J, Zhao W, You Y, Yang X. The 2002 China Nutrition and Health Survey: quality control. Chinese Journal of Epidemiology 2005; 26: 474-8.

21 National Bureau of Statistics of China. China Statistical Yearbook 2002. Beijing: China Statistics Press, 2000; 8(1).

22 Zhang Q. Iron nutritional status of young female workers in Shanghai First Silk Factory. Chinese Journal of Preventive Medicine 1987; 2: 87-9.
23 Cai M, Yan WY. Study on iron nutritional status in adolescence. Biomedical and Environmental Sciences 1990; 3: 113-19.

24 Wang W, Wang JM, Bian L, Song J, Yang W. Studies on iron deficiency anemia of primary school children in a rural area of Beijing. Journal of Hygiene Research 1990; 19: 31-2.

25 He Y, Wang H, Hu Z, Lin Y. Study on nutritional anemia in students of 7 nationalities in Xinjiang autonomous. Xinjiang Hygiene and Prevention 1994; 12: 1-6.

26 World Health Organization (WHO). Physical Status: The Use and Interpretation of Anthropometry. Report of a WHO Expert Committee. Technical Report Series No. 854. Geneva: WHO, 1995.

27 WHO Working Group. Use and interpretation of anthropometric indicators of nutritional status. Bulletin of the World Health Organization 1986; 64: 929-41.

28 Yang Y, Wang G, Pan X. China Food Composition Table 2002. Beijing: Beijing Medical University Publishing House, 2002.

29 Food and Agriculture Organization of the United Nations (FAO)/World Health Organization (WHO). Human Vitamin and Mineral Requirements. Report of a Joint FAO/WHO Expert Consultation. Rome: FAO, 2002.

30 Ma G, Jin Y, Piao J, Kok JF, Bonnema G, Jacobsen E. Phytate, calcium, iron and zinc contents and their molar ratio in foods commonly consumed in China. Journal of Agricultural and Food Chemistry 2005; 53: 10285-90.

31 Ma G, Li Y, Jin Y, Zhai F, Kok FJ, Yang X. Phytate intake and molar ratios of phytate to zinc, iron and calcium in the diets of people in China. European Journal of Clinical Nutrition 2007; 61: 368-74.

32 Ma G, Li Y, Jin Y, Du S, Kok FJ, Yang X. Assessment of zinc intake adequacy and food source of people in China. Public Health Nutrition 2007; 10: 845-54.

33 Block G, Dresser CM, Hartman AM, Carroll MD. Nutrient sources in the American diet: quantitative data from the NHANES II survey. American Journal of Epidemiology 1985; 122: 13-26.

34 Murray CJ, Evans DB, Acharya A, Baltussen RM. Development of WHO guidelines on generalized cost-effectiveness analysis. Health Economics 2000; 9: 235-51.

35 World Health Organization. CHOosing Interventions that are Cost Effective (WHO-CHOICE) [online]. Available at http://www.who.int/choice. Accessed 18 March 2005.

36 Murray CJ, Lauer JA, Hutubessy RC, Niessen L, Tomijima N, Rodgers A, et al. Effectiveness and cost of interventions to lower systolic blood pressure and cholesterol: a global and regional analysis on reduction of cardiovascular-disease risk. Lancet 2003; 361: 717-25.

37 Bouis HE. Micronutrient fortification of plants through plant breeding: can it improve nutrition in man at low cost? Proceedings of the Nutrition Society 2003; 62: 403-11.

38 Ministry of Agriculture of the People's Republic of China. Planting area and output of staple crops in China [online]. Available at http://www.agri.gov.cn/sjzl/nongyety.htm. Accessed 20 March 2006.

39 World Bank. Enriching Lives: Overcoming Vitamin and Mineral Malnutrition in Developing Countries. Development in Practice Series. Washington, DC: World Bank, 1994.

40 Horton S. The economics of food fortification. Journal of Nutrition 2005; 136: 1068-71.

41 The Micronutrient Initiative/United Nations Children's Fund (UNICEF). Vitamin \& Mineral Deficiency: A Global Progress Report. Ottawa/New York: The Micronutrient Initiative/ UNICEF, 2003.

42 Hallberg L, Rossander L. Improvement of iron nutrition in developing countries: comparison of adding meat, soy protein, ascorbic acid, citric acid, and ferrous sulphate on iron absorption from a simple Latin American-type of meal. American Journal of Clinical Nutrition 1984; 39: 577-83. 
43 Suharno D, West CE, Muhilal, Karyadi D, Hautvast JG. Supplementation with vitamin A and iron for nutritional anaemia in pregnant women in West Java, Indonesia. Lancet 1993; 342: 1325-8.

44 Ridwan E, Schultink W, Dillon D, Gross R. Effects of weekly iron supplementation on pregnant Indonesian women are similar to those of daily supplementation. American Journal of Clinical Nutrition 1996; 63: 884-90.

45 Brown K, Peerson JM, Allen LH. Effects of zinc supplementation on children's growth. In: Sandström B, Walter P, eds. Role of Trace Elements for Health Promotion and Disease Prevention [special issue]. Bibliotheca Nutritio et Dieta 1998; 54: 76-83.

46 McGuire J. Addressing micronutrient malnutrition. SCN News 1993; 9: 1-0.

47 Yip R. Iron deficiency: contemporary scientific issues and international programmatic approaches. Journal of Nutrition 1994; 124: 1479S-90S.

48 Stoltzfus R, Dreyfuss M. Guidelines for the Use of Iron Supplements to Prevent and Treat Iron Deficiency Anemia. The International Nutrition Anemia Consultative Group (INACG). Washington, DC: ILSI Press, 1998; 39 pp.

49 Mertz W. Food fortification in the United States. Nutrition Reviews 1997; 55: 44-9.

50 Honein MA, Paulozzi LJ, Mathews TJ, Erickson JD, Wong LY. Impact of folic acid fortification of the US food supply on the occurrence of neural tube defects. JAMA: Journal of the American Medical Association 2001; 285: 2981-6.

51 Ray JG, Meier C, Vermeulen MJ, Boss S, Wyatt PR, Cole DE. Association of neural tube defects and folic acid food fortification in Canada. Lancet 2002; 360: 2047-8.
52 Allen LH. New approaches for designing and evaluating food fortification programs. Journal of Nutrition 2006; 136: $1055-8$.

53 Haas JH, Miller DD. Overview of experimental biology 2005 symposium: food fortification in developing countries. Journal of Nutrition 2006; 136: 1053-4.

54 Chen J, Zhao X, Zhang X, Yin S, Piao J, Huo J, et al. Studies on the effectiveness of NaFeEDTA-fortified soy sauce in controlling iron deficiency: a population-based intervention trial. Food and Nutrition Bulletin 2005; 26: 177-86.

55 Copenhagen Consensus. Copenhagen consensus - vision and facts [online], 2004. Available at http://www.copenhagenconsensus.com. Accessed 28 February 2005.

56 Zhai F, He Y, Ma G, Li Y, Wang Z, Hu Y, et al. Study on the current status and trend of food consumption among Chinese population. Chinese Journal of Epidemiology 2005; 26: 485-8.

57 Haas JD, Beard JL, Murray-Kolb L, del Mundo A, Felix A, Gregorio G. Iron-biofortified rice increase body iron in Filipino women. Journal of Nutrition 2005; 135: 2823-30.

58 Bouis HE. Global efforts to breed for more nutritious crops. In: Roos N, Bouis HE, Hassan H, Kabir KA, eds. Alleviating Malnutrition Through Agriculture in Bangladesh. Washington, DC: International Food Policy Research Institute, 2004; 28-34.

59 Welch RM. Biotechnology, biofortification, and global health. Food and Nutrition Bulletin 2005; 26: 419-21.

60 Caballero B. Fortification, supplementation, and nutrient balance. European Journal of Clinical Nutrition 2003; 57: S76-8. 